\title{
STEAM REFORMING OF UPGRADED BIO-OIL AQUEOUS PHASE FRACTION FROM SUNFLOWER SEED HULLS: THERMODYNAMIC ANALYSIS
}

\author{
Y. P. MAIDANA ${ }^{\S}$, E. M. IZURIETA ${ }^{\dagger, \S}$, A. I. CASONI ${ }^{\ddagger}, \S$ \\ M. A. VOLPE ${ }^{\ddagger}$, , E. LÓPEZ ${ }^{\S}$ AND M. N. PEDERNERA ${ }^{\dagger, \S}$ \\ $\dagger$ Departamento de Ingeniería Química, Universidad Nacional del Sur (UNS) \\ \$ Departamento de Química, Universidad Nacional del Sur (UNS) \\ $\S$ Planta Piloto de Ingeniería Química - PLAPIQUI(UNS-CONICET) \\ eizurieta@plapiqui.edu.ar
}

\begin{abstract}
This work focuses on the study of hydrogen production process departing from waste lignocellulosic biomass. The bio-oil was first obtained by non-catalytic fast pyrolysis of sunflower seed hulls. Subsequently, it was upgraded to reduce the concentration of higher molecular weight compounds by water addition and mixing. A 1/1 bio-oil: water ratio was selected here. Later, a thermodynamic analysis based on free energy minimization was profited to study the steam reforming process of the upgraded bio-oil sample. The influence of the operation temperature on the reforming was analyzed. The highest hydrogen yields were obtained at $\sim 740^{\circ} \mathrm{C}$. A comparison with acetic acid used as model compound of the bio-oil is included. Results show that acetic acid is not a good approximation of a real aqueous phase of upgraded bio oil fraction. The study concludes with an analysis on the energetic efficiency, showing that its maximum is presented at lower temperatures than the maximum yield, due to the thermal requirements of preheating.
\end{abstract}

Keywords - Hydrogen, Thermodynamic analysis, Bio-oil, Steam reforming.

\section{INTRODUCTION}

In a global context characterized by population increase and the fast growing in per capita consumption in emergent countries, a wide variety of alternatives to satisfy the high demand of energy have been proposed. Hydrogen, apart from being a fundamental raw material in metallurgical, chemical and petrochemical industries, is a promising energy carrier for the future. The main sources of $\mathrm{H}_{2}$ nowadays are not renewable, fossil fuels as $\mathrm{CH}_{4}$, which is reacted in large-scale facilities with steam and/or air by different reforming process. By these means, syngas $\left(\mathrm{H}_{2}+\mathrm{CO}\right)$ is formed and further purified if required. In the actual context of increasing energy requirements and environmental concerns, biofuels have been pointed as promissory alternatives as non-fossil raw material sources. Although extensive knowledge about first generation biofuels is currently available (Naik et al., 2010), the development of other options is needed. Among them, second generation biofuels, which include lignocellulosic biomass as raw material, result of interest. This type of biomass is generally obtained from agro-industrial, agricultural activities, forest waste products, and even from ad hoc crops (Naik et al., 2010). As a renewable energy source, biomass is cost-effective, presents an almost neutral $\mathrm{CO}_{2}$ balance and generates remarkably low $\mathrm{SO}_{2}$ and $\mathrm{NO}_{\mathrm{x}}$ emissions (Chen et al., 2011).

Bio-oil is the liquid fraction obtained from capturing the condensable gases exiting the pyrolysis unit. Storage and transportation of bio-oil are simpler than those of a gas (pyrolytic or by gasification of biomass) or raw biomass. As a disadvantage, it presents a polar character, and it is corrosive and viscous (Naik et al., 2010). Bio-oil can be obtained by fast pyrolysis of sunflower seed hulls (SSH) as a complex mixture of different organic compounds such as acids of low molecular weight, ketones, aldehydes, furans, alcohols, phenols, aromatics, other acids of high molecular weight, esters and sugars (Casoni et al., 2015), and subsequently fed to a steam reforming reactor to achieve a stream rich in hydrogen. The bio-oil used to feed catalytic steam reforming processes has a strong tendency to form carbonaceous depositions leading to the deactivation of the catalysts (Takanabe et al., 2006). Numerous alternatives have been proposed in literature to mitigate this problem (Xiu and Shahbazi, 2012). Among others, the addition of water to the bio-oil in order to separate the light compounds (aqueous phase) from tar (oily phase) is profited (Scholze and Meier, 2001). The hydrophobic phase contains the products derived from lignin, while the aqueous phase mainly contains the species derived from holocellulose: acids, ketones, aldehydes, etc. (Yan et al., 2010). Normally, the aqueous fraction does not have specific applications; its reforming to produce streams rich in hydrogen can increment its economic value (Resende et al., 2015). After obtained and conveniently upgraded, the bio-oil can be converted into different products; the study of the transformation of aqueous phase of upgraded bio-oil fraction into syn-gas or hydrogen by steam reforming (SR) is the main aim of this work.

Several works reporting steam reforming of real biooil from pyrolysis biomass or its aqueous phase can be found (Remiro et al., 2014; Valle et al., 2013; Wu et al., 2008). Because of the complexity of real bio-oil, model compounds or synthetic bio-oil are normally used to study the steam reforming of bio-oil (Wang et al., 1997). Acetic acid has been widely studied as model compound, since it is reported as the most abundant compound in bio-oil mixtures (Esteves Nogueira et al., 2014; Galdá- 
mez et al., 2005); acetol, acetone, phenol, among others, have been used as well (González-Gil et al., 2015; TraneRestrup et al., 2015; Xu et al., 2013).

Regarding thermodynamic studies of reforming of model compounds, the following works can be mentioned using acetic acid, methanol, ethylene glycol, acetone, ethanol, n-butanol, acetol, glycerol, phenol, syringol, furfural, isopropyl alcohol or lactic acid (Aktaş et al., 2009; Goicoechea et al., 2015; Lima Da Silva and Müller, 2011; Resende et al., 2015; Vagia and Lemonidou, 2007; Xie et al., 2014). Contrasting this number of papers, remarkably less references considering model mixtures with the main compounds of bio-oil are found (Montero et al., 2015; Resende et al., 2015).

Resende et al. (2015) conducted an interesting thermodynamic analysis of steam reforming of model compound and synthetic aqueous fraction of bio-oil. This aqueous phase was based on the average composition of the aqueous fraction obtained from pyrolysis of various feedstocks. Similarly, Domine et al. (2008) calculated the thermodynamic equilibrium composition for bio-oil steam reforming, assuming a simplified bio-oil mixture with seventeen oxygenated of the main bio-oil components and water, to match the ratio $\mathrm{C}: \mathrm{H}: \mathrm{O}$ revealed by the elemental analysis of their real bio-oil sample. The research of Montero et al. (2015) involves a thermodynamic study of steam reforming of a synthetic bio-oil composed of model species from real bio-oil components.

Thermodynamic analyses of steam reforming of real bio-oils from different raw sources is remarkably scarce. Even further, to our best knowledge, literature studies focusing the steam reforming of bio-oils derived from pyrolysis of sunflower seed hulls have not been published.

This contribution presents a thermodynamic study of steam reforming of the aqueous phases of real bio-oils from fast pyrolysis of SSH. The influence of the operative variables on the distribution of products from SR was analyzed through a Gibbs free energy minimization strategy. Additionally, the amount of deposited carbon as predicted by thermodynamics is estimated in the different operative conditions.

\section{METHODS}

\section{A. Fast pyrolysis of sunflower seed hulls and bio-oil upgrading}

Sunflower seed hulls were profited as biomass to feed the pyrolysis reactor. This lignocellulosic material presented a moisture content of $6 \%$ (OHAUS MB45). Before pyrolysis, the hulls were milled to particles in the range of $250 \mu \mathrm{m}$ (HORIBA LA-950).

The pyrolytic reaction was performed in a vertical glass reactor implemented into an electric furnace previously heated at $430{ }^{\circ} \mathrm{C}$. Nitrogen was employed as carrier gas, fed from the top of the reactor at $200 \mathrm{~mL} / \mathrm{min}$. The vapors downstream the reactor were condensed in an ice/water bath. The experimental conditions were selected to maximize the yield of liquid. A detailed description of pyrolysis process and bio-oil characterization is given elsewhere (Casoni et al., 2015)

The upgrading of the obtained bio-oil was carried out by mixing this liquid with water at a bio-oil/water mass ratio following a previous report in literature: $1 / 1 \mathrm{w} / \mathrm{w}$ (Rasrendra et al., 2011). To these ends, bio-oil was added dropwise to water previously cooled at $0{ }^{\circ} \mathrm{C}$ in a water/ice bath. The mixture was maintained under continuous stirring for $15 \mathrm{~min}$ in order to precipitate a paste-like phase (Park et al., 2016) composed mainly by methoxy-phenols. On the other side, the aqueous phase retains the lowweight species, with acetic acid appearing as the major component. Through this approach, the upgraded bio-oil presented a much simpler composition than the original bio-oil.

The chemical compositions of the original and upgraded bio-oils were quantified using a GC-MS Perkin Elmer CLARUS 500 chromatograph, equipped with an Elite-5 MS column (60 m, $0.25 \mathrm{~mm}$ ID and $0.25 \mu \mathrm{m} \mathrm{df})$. The method comprised an initial temperature of $65^{\circ} \mathrm{C}$ held for $5 \mathrm{~min}$ followed by a ramp of $30^{\circ} \mathrm{C} / \mathrm{min}$ up to $280{ }^{\circ} \mathrm{C}$ held for $0.83 \mathrm{~min}$. Towards the identification of chromatographic peaks, the NIST MS library was profited (global matches higher than 800).. The water content of the original bio-oil amounted 11\% w/w (Karl-Fischer).

\section{B. Free energy minimization as a tool for computing chemical equilibrium}

The equilibrium composition of the reaction mixture was calculated by minimization of Gibb's free energy (Elliott and Lira, 2012). Carbon deposition is a strong restriction in reforming processes leading to deactivation of the reforming catalysts. Then, the inclusion of the prediction of solid carbon formation in the analysis acquires an outstanding relevance. This work considers the carbon modeled as graphite. Graphite presents a null Gibbs energy and a vapor pressure low enough as to be neglected it from the energy minimization. However, graphite cannot be omitted in the atomic balance of carbon.

Several studies regarding bio-oil steam reforming (BSR) (Aktaş et al., 2009; Lima Da Silva and Müller, 2011; Montero et al., 2015) have proved that at high enough residence times the gaseous mixture exiting the reactor is composed by $\mathrm{H}_{2}, \mathrm{H}_{2} \mathrm{O}, \mathrm{CO}, \mathrm{CO}_{2}$, and $\mathrm{CH}_{4}$, with negligible amounts of $\mathrm{C}_{2+}$ species, even at low temperature. As mentioned, the prediction of appearance of carbonaceous depositions was also considered.

\section{Energetic evaluation}

The reaction performance at equilibrium is evaluated through the yields $\left(\eta_{i}\right)$ of the different products:

$$
\eta_{i}=\frac{n_{i}}{n_{B O}^{0}}
$$

where $n_{i}$ corresponds to the molar quantities of each of the $i$ species present in the output mixture, including the moles of solid carbon generated. $n_{B O}^{0}$ represents the molar quantity of the bio-oil fed to the reactor. The overall energy requirement of the process of bio-oil steam reforming is evaluated here through the thermal efficiency $(\varphi)$, according to: 


$$
\varphi=\frac{n_{H_{2}}}{Q_{T}}
$$

where $Q_{T}$ amounts the reaction heat plus the heat required to preheat and evaporate the reactive mixture from $25^{\circ} \mathrm{C}$ up to the reaction temperature:

$$
Q_{T}=\sum_{\text {products }}\left(n_{i} \cdot H_{i}\right)_{T}-\sum_{\text {reactives }}\left(n_{i} \cdot H_{i}\right)_{298 \mathrm{~K}}
$$

where $H_{i}$ is the molar enthalpy of each species at the correspondent temperature.

\section{RESULTS}

Table 1 shows the chemical composition in dry basis of the original and upgraded bio-oils (OR-BO and UP-BO, respectively). The original bio-oil presented a typical lignocellulosic composition, i.e., a relatively high concentration of acids, furans and methoxy-phenols, with average molecular formula $\mathrm{C}_{4.55} \mathrm{H}_{6.65} \mathrm{O}_{1.92}$. It is worth mentioning that methoxy-phenols turn these liquids unstable upon storage due to repolymerization reactions. As seen from Table 1, these heavy compounds have been depleted when analyzing the aqueous phase from the upgrading. In this way, a more stable liquid is achieved. Moreover, the acetic acid fraction rises from $39 \% \mathrm{w} / \mathrm{w}$ of the original bio-oil to $45 \% \mathrm{w} / \mathrm{w}$ for the upgraded sample. The average molecular formula for the UP-BO is $\mathrm{C}_{3.30} \mathrm{H}_{5.28} \mathrm{O}_{1.92}$.

\section{A. Steam reforming of upgraded samples and model compounds}

Figure 1 shows the equilibrium yields of the products for the steam reforming of the upgraded bio-oil as a function of the reaction temperature. The calculations were performed at a pressure of 1.2 bar. A steam-to-carbon ratio (STC) of 1.59 resulted for the UP-BO sample, slightly above the stoichiometric value of 1.42 , considering the carbon amount present in the mixture.

The equilibrium mixture from steam reforming of UP-BO points that at the lowest temperatures under study (i.e., $300 \mathrm{C}<\mathrm{T}<350 \mathrm{C}$ ), the upgraded bio-oil is decomposed in an almost equimolar mixture of $\mathrm{CO}_{2}$ and $\mathrm{CH}_{4}$, possibly through a decarboxylation reaction of acetic acid, which, as mentioned, constituted the major compound of the UP-BO.

The evaluation and quantification of carbonaceous depositions are of interest since the phenomena represents one of the main restrictions for the steam reforming process implementation. From the thermodynamics approach, an operation temperature lower than $480{ }^{\circ} \mathrm{C}$ for the UP-BO (STC 1.59) ensures carbonaceous formations and must be avoided. Furthermore, the high $\eta_{\mathrm{CH}_{4}}$ leads to a very low $\eta_{H_{2}}$ in this temperature range.

As temperature increases (up to approximately $550{ }^{\circ} \mathrm{C}$ ), both steam reforming and cracking of the oxygenated compounds of bio-oil take place, leading to a decrease in $\mathrm{CH}_{4}$ yield and an increase in $\mathrm{H}_{2}$ and $\mathrm{CO}_{2}$ yields. Above $550{ }^{\circ} \mathrm{C}, \mathrm{CH}_{4}$ reforming continues and some of the formed $\mathrm{H}_{2}$ and $\mathrm{CO}_{2}$ are consumed by the reverse water gas shift reaction. Around $\mathrm{T}=740{ }^{\circ} \mathrm{C}$, the $\mathrm{H}_{2}$ yield attains a maximum, matching with methane total depletion. The highest hydrogen yield reaches at $740 \mathrm{C}$ a value of 5.23, which represents a $71.5 \%$ of the theoretical stoichiometric value of 7.32. Finally, at temperatures higher than $740 \mathrm{C}$ the remaining reaction is the reverse WGS, yielding an unwanted consume of $\mathrm{H}_{2}$.

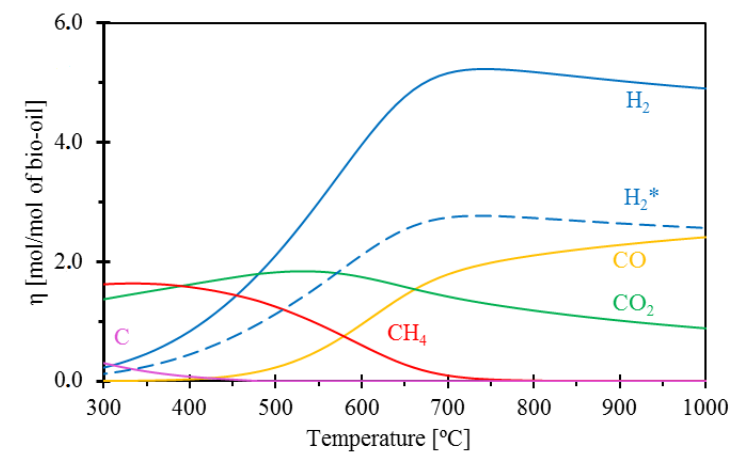

Figure 1: Yields of products in the BSR of the UP-BO as a function of the temperature, and its comparison with acetic $\operatorname{acid}(*)$.

Table1. Chemical composition of original (OR-BO) and upgraded (UP-BO) bio-oils from SSH pyrolysis.

\begin{tabular}{lrr}
\multicolumn{1}{c}{ Compound name } & OR-BO & UP-BO \\
\hline formic acid & 0.63 & - \\
acetic acid & 38.99 & 45.2 \\
methyl acetate & 2.77 & 2.54 \\
propionic acid & 0.42 & 3.21 \\
2-methylpropan-1-ol & 1.41 & 2.06 \\
3-hydroxybutanone & 4.99 & 7.59 \\
2,3-butanodione & 2.16 & 3.17 \\
furfural & 8.5 & 10.36 \\
2-furanmethanol & 2.3 & 2.84 \\
2-cyclopenten-1-one,2-methyl- & 1.16 & - \\
2(5H)furanone & 2.32 & 2.05 \\
2-cyclopenten-1-one & 3.04 & 3.33 \\
phenol & 1.12 & - \\
4-heptanone & 1.84 & - \\
2-ethyl-2-cyclopentenone-1-one & 2.93 & 3 \\
2-methoxy-phenol & 6.61 & 7.86 \\
2-hepten-4-ol & 2.98 & 1.84 \\
phenol,2-methoxy-4-methyl & 2.44 & 2.48 \\
levoglucosan & 0.6 & - \\
1,2-benzenediol,3-methoxy & 0.41 & - \\
phenol,5-ethyl-2-methoxy & 1.2 & - \\
3-isopropylcatechol & 2.92 & 2.47 \\
2,6-dimethoxy-phenol & 1.72 & - \\
eugenol & 0.34 & - \\
isovanilin & 0.99 & - \\
isoeugenol & 1.48 & - \\
guaiacylacetone & 1.26 & - \\
phenol, 3-tert-butyl-4-methoxy- & 1.06 & - \\
4-hexyl-guaiacol & 0.66 & - \\
acetovanillone & 0.73 & - \\
\hline & & \\
\hline
\end{tabular}


Concerning the carbon formation, its presence is thermodynamically predicted at low temperature as consequence of both the Boudouard reaction and the thermal decomposition of bio-oil. However, operation at temperatures above $480 \mathrm{C}$ assures negligible amounts of carbon depositions.

As already mentioned, acetic acid is usually selected as model compound to represent the complex bio-oil mixture since it is the major species. Therefore, for comparative purposes the $\mathrm{H}_{2}$ yield from acetic acid SR has been incorporated into Fig. 1. The calculations were performed by using in the same operating conditions as selected for the steam reforming of bio-oil, i.e. pressure of 1.2 bar and $12 \%$ water excess. Under these conditions, the STC ratio for the acetic acid is 1.12 , slightly above the stoichiometric value of 1.0. The distribution of products, not shown in Fig. 1, responds to the values found in literature as expected (Goicoechea et al., 2015; Vagia and Lemonidou, 2007). The hydrogen yield for acetic acid SR shows a similar tendency to the already discussed corresponding to the UP-BO sample. However, the values are clearly inferior for the whole temperature range under study. In fact, the maximum yield for acetic acid is verified at the same temperature $\left(740{ }^{\circ} \mathrm{C}\right)$ but the value achieved $\left(\eta_{H_{2}}=2.77,69.3 \%\right.$ of the stoichiometric value of 4.0) is considerably lower than the maximum yield for UP-BO $\left(\eta_{H_{2}}=5.23\right)$. As seen, although acetic acid is the major compound of the upgraded sample, the species of higher molecular weight should not be neglected for SR processes.

Aiming to extend the analysis of the steam reforming performance of the upgraded sample, different levels of water addition post-upgrading have been studied (i.e., UP-BO + additional water). Figure 2 presents contours of hydrogen yield at different STC ratios as influenced by the reaction temperature. As expected, a positive influence of increasing the STC ratio on the hydrogen yield is observed. In line with the discussion of Fig. 1, for a fixed STC, as the temperature rises, so does the yield to hydrogen, until reaching a maximum. The set of maxima is plotted with a discontinuous line in Fig. 2. Reforming reactions prevail in the region to the left of the dotted line while operating points located to the right imply hydrogen losses due to the reverse WGS reaction.

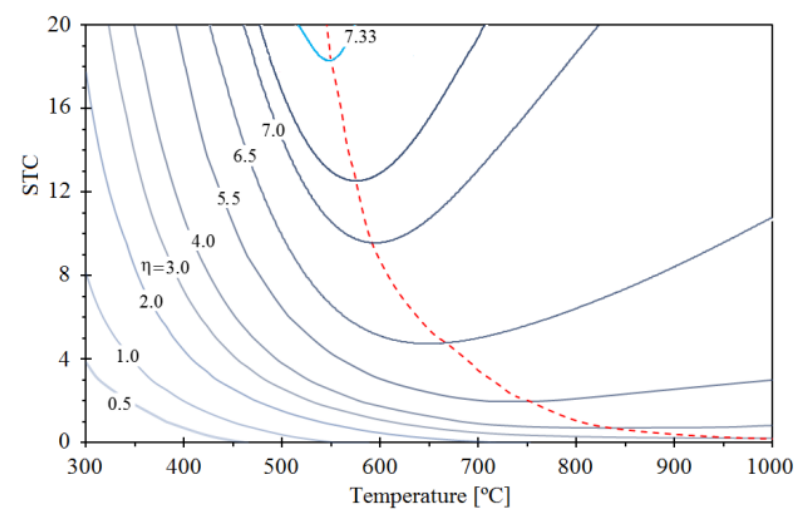

Figure 2: Hydrogen yield for the SR of the UP-BO, as a function of temperature and STC.

\section{B. Thermal efficiency}

The thermal efficiency $(\varphi)$ and $\mathrm{H}_{2}$ yield $\left(\eta_{\mathrm{H}_{2}}\right)$ from the steam reforming of the UP-BO at different temperatures are presented in Fig. 3. As shown, the thermal efficiency grows with temperature up to a maximum of $\varphi=6.85 \mathrm{~mol} / \mathrm{MJ}$, observed at $\mathrm{T}=660^{\circ} \mathrm{C}$. Since the main heat requirement is associated to the evaporation and preheating of the mixture, the augment of the efficiency attached to the increase in hydrogen yield seems reasonable. However, the condition of maximum $\mathrm{H}_{2}$ yield occurs at a higher temperature $\left(\mathrm{T}=740^{\circ} \mathrm{C}\right.$ with $\left.\eta_{\mathrm{H}_{2}}=5.23\right)$. In fact, at $\mathrm{T}>660^{\circ} \mathrm{C}, \eta_{\mathrm{H}_{2}}$ remains almost constant while the heat requirement naturally associated to the evaporation and preheating increase. Therefore, thermal efficiency drops with the thermal level. This effect is even more pronounced after the maximum $\mathrm{H}_{2}$ yield occurs (i.e., $\mathrm{T}>$ $740^{\circ} \mathrm{C}$ ).

Considering that the energy requirement is strongly influenced by the water content in the UP-BO, the analysis has been extended for the steam reforming of the sample with a modified STC ratio (via extra water addition or water subtraction once the sample has been achieved by upgrading of the original bio-oil). Figure 4 shows contour lines of thermal efficiency as a function of the reforming temperature and the modified STC ratio.

Although an increase in the water content in the feed (i.e., increasing STC ratios) leads to higher yields of hydrogen (see Fig. 2), even higher amounts of energy for evaporation and preheating are required. Consequently, the efficiency decreases with STC for the whole range of temperatures under study.

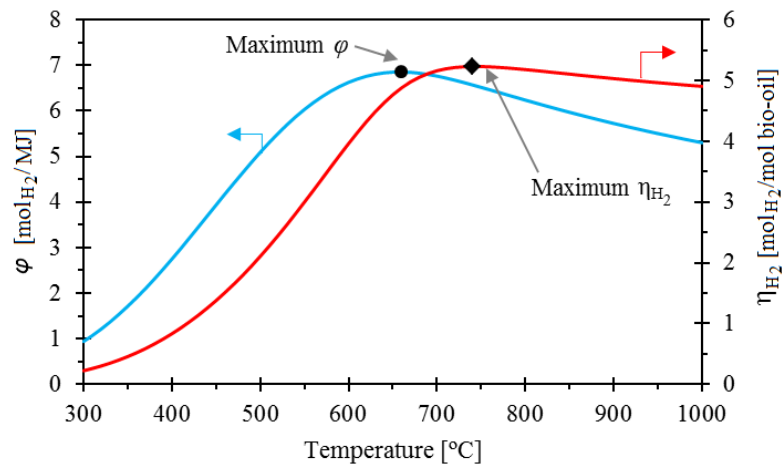

Figure 3: Thermal efficiency $(\varphi)$ and hydrogen yield $\left(\eta_{H_{2}}\right)$, as a function of temperature. STC $=1.59$.

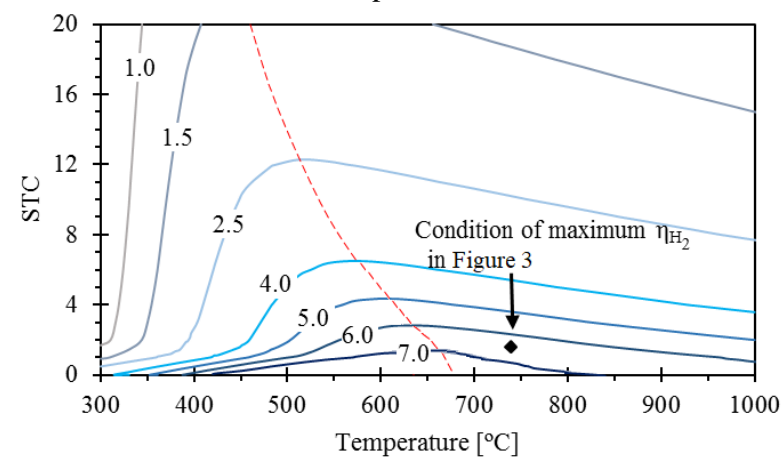

Figure 4: Contours of thermal efficiency, $\varphi,[\mathrm{mol} / \mathrm{MJ}]$, as influenced by temperature and STC. 
The analysis of the influence of the temperature on $\varphi$ can be separated in two zones, which are limited by the dashed line in Figure 4 representing the locus of maximum thermal efficiencies. On the region located to the left of the dashed line, the augment in the thermal efficiency with temperature is governed by the increase in the hydrogen yield. To the right of the dashed line, both the drop in the hydrogen yield (as seen in Fig. 2) and the higher energy requirements to preheat the reactive mixture lead to a drop in $\varphi$. As already mentioned, the maxima of $\varphi$ and $\eta_{H_{2}}$ are not overlapped, appearing the correspondent to $\varphi$ at lower temperatures than $\eta_{H_{2}}$ for a given condition of STC ratio (The maximum $\eta_{\mathrm{H}_{2}}$ of Fig. 3 is reported in Fig. 4 to exemplify this behavior).

\section{CONCLUSIONS}

This paper presents a study of the hydrogen production by steam reforming of bio-oil fractions from fast pyrolysis of sunflowers seed hulls. A thermodynamic analysis was performed on steam reforming of upgraded bio-oil aqueous fractions obtained by water addition to the original bio-oil sample.

A Gibbs free energy minimization strategy was profited here towards studying the influence of the operating variables on the performance of the steam reforming of the upgraded bio-oil sample (i.e., temperature and steamto-carbon (STC) ratio). Overall, the steam reforming of the upgraded bio-oil showed a good performance producing high hydrogen yields. Operation temperature lower than $480{ }^{\circ} \mathrm{C}$ ensures carbonaceous depositions and must be avoided.

We also studied here the steam reforming of acetic acid as model compound of bio-oil (which is a common practice through the literature). It was concluded that, although similar behavior trends were observed, it provides a poor quantitative representation of the upgraded bio-oil sample in terms of hydrogen yield.

The steam reforming presented a gap in temperatures between the maximums of thermal efficiency and hydrogen yield. Then, the optimum temperature for steam reforming of the prepared bio-oil sample is in the range $660^{\circ} \mathrm{C}<\mathrm{T}<740^{\circ} \mathrm{C}$. Post-upgrading water addition leads to a hydrogen yield increase, but, however, higher energy requirements cause a decrease in thermal efficiency.

\section{ACKNOWLEDGEMENTS}

The authors acknowledge the financial support of Consejo Nacional de Investigaciones Científicas y Técnicas, CONICET.

\section{REFERENCES}

Aktaş, S., Karakaya, M. and Avci, A.K. (2009). “Thermodynamic analysis of steam assisted conversions of bio-oil components to synthesis gas," Int. J. Hydrogen Energy, 34, 1752-1759.

Casoni, A.I., Bidegain, M., Cubitto, M.A., Curvetto, N. and Volpe, M.A. (2015). "Pyrolysis of sunflower seed hulls for obtaining bio-oils," Bioresour. Technol., 177, 406-409.
Chen, T., Wu, C. and Liu, R. (2011). "Steam reforming of bio-oil from rice husks fast pyrolysis for hydrogen production," Bioresour. Technol., 102, 92369240.

Domine, M.E., Iojoiu, E.E., Davidian, T., Guilhaume, N. and Mirodatos, C. (2008). "Hydrogen production from biomass-derived oil over monolithic Pt- and Rh-based catalysts using steam reforming and sequential cracking processes," Catal. Today, 133135, 565-573.

Elliott, J.R. and Lira, C.T. (2012). Introductory Chemical Engineering Thermodynamics, $2^{\text {nd }}$ ed., Prentice Hall, New Jersey.

Esteves Nogueira, F.G., Assaf, P.G., Carvalho, H.W. and Assaf, E.M. (2014). "Catalytic steam reforming of acetic acid as a model compound of bio-oil," Appl. Catal. B Environ., 160-161, 188-199.

Galdámez, J.R., García, L. and Bilbao, R. (2005). "Hydrogen production by steam reforming of bio-oil using coprecipitated Ni-Al catalysts. Acetic acid as a model compound," Energy and Fuels, 19, 11331142.

Goicoechea, S., Ehrich, H., Arias, P.L. and Kockmann, N. (2015). "Thermodynamic analysis of acetic acid steam reforming for hydrogen production," $J$. Power Sources, 279, 312-322.

González-Gil, R., Chamorro-Burgos, I., Herrera, C., Larrubia, M.A., Laborde, M.Á., Mariño, F.J. and Alemany, L.J. (2015). "Production of hydrogen by catalytic steam reforming of oxygenated model compounds on Ni-modified supported catalysts. Simulation and experimental study," Int. J. Hydrogen Energy, 40, 11217-11227.

Lima Da Silva, A. and Müller, I.L. (2011). "Hydrogen production by sorption enhanced steam reforming of oxygenated hydrocarbons (ethanol, glycerol, nbutanol and methanol): Thermodynamic modelling," Int. J. Hydrogen Energy, 36, 2057-2075.

Montero, C., Oar-Arteta, L., Remiro, A., Arandia, A., Bilbao, J. and Gayubo, A.G. (2015). "Thermodynamic comparison between bio-oil and ethanol steam reforming," Int. J. Hydrogen Energy, 40, 15963-15971.

Naik, S.N., Goud, V. V., Rout, P.K. and Dalai, A.K. (2010). "Production of first and second generation biofuels: A comprehensive review," Renew. Sustain. Energy Rev., 14, 578-597.

Park, L.K., Ren, S., Yiacoumi, S., Ye, X.P., Borole, A.P. and Tsouris, C. (2016). "Separation of switchgrass bio-oil by water/organic solvent addition and $\mathrm{pH}$ adjustment," Energy and Fuels, 30, 2164-2173.

Rasrendra, C.B., Girisuta, B., Van de Bovenkamp, H.H., Winkelman, J.G.M., Leijenhorst, E.J., Venderbosch, R.H., Windt, M., Meier, D. and Heeres, H.J. (2011). "Recovery of acetic acid from an aqueous pyrolysis oil phase by reactive extraction using trin-octylamine," Chem. Eng. J., 176-177, 244-252. 
Remiro, A., Valle, B., Oar-Arteta, L., Aguayo, A.T., Bilbao, J. and Gayubo, A.G. (2014). "Hydrogen production by steam reforming of bio-oil/bio-ethanol mixtures in a continuous thermal-catalytic process," Int. J. Hydrogen Energy, 39, 6889-6898.

Resende, K.A., Ávila-Neto, C.N., Rabelo-Neto, R.C., Noronha, F.B. and Hori, C.E. (2015). "Thermodynamic analysis and reaction routes of steam reforming of bio-oil aqueous fraction," Renew. Energy, 80, $166-176$.

Scholze, B. and Meier, D. (2001). "Characterization of the water-insoluble fraction from pyrolysis oil (pyrolytic lignin). Part I. PY-GC/MS, FTIR, and functional groups," J. Anal. Appl. Pyrolysis, 60, 41-54.

Takanabe, K., Aika, K.-I., Inazu, K., Baba, T., Seshan, K. and Lefferts, L. (2006). "Steam reforming of acetic acid as a biomass derived oxygenate: Bifunctional pathway for hydrogen formation over $\mathrm{Pt} / \mathrm{ZrO} 2$ catalysts," J. Catal., 243, 263-269.

Trane-Restrup, R., Jensen, A.D., Degn Jensen, A. and Jensen, A.D. (2015). "Steam reforming of cyclic model compounds of bio-oil over Ni-based catalysts: Product distribution and carbon formation," Appl. Catal. B Environ., 165, 117-127.

Vagia, E.C. and Lemonidou, A.A. (2007). "Thermodynamic analysis of hydrogen production via autothermal steam reforming of selected components of aqueous bio-oil fraction," Int. J. Hydrogen Energy, 32, 212-223.

Valle, B., Remiro, A., Aguayo, A.T., Bilbao, J. and Gayubo, A.G. (2013). "Catalysts of $\mathrm{Ni} / \alpha-\mathrm{Al}_{2} \mathrm{O}_{3}$ and $\mathrm{Ni} / \mathrm{La}_{2} \mathrm{O}_{3}-\alpha \mathrm{Al}_{2} \mathrm{O}_{3}$ for hydrogen production by steam reforming of bio-oil aqueous fraction with pyrolytic lignin retention," Int. J. Hydrogen Energy, 38, 1307-1318.

Wang, D., Czernik, S., Montane, D., Mann, M., Chornet, E., Montané, D., Mann, M. and Chornet, E. (1997). "Biomass to hydrogen via fast pyrolysis and catalytic steam reforming of the pyrolysis oil or its fractions," Abstr. Pap. Am. Chem. Soc., 36, 1507-1518.

Wu, C., Huang, Q., Sui, M., Yan, Y. and Wang, F. (2008). "Hydrogen production via catalytic steam reforming of fast pyrolysis bio-oil in a two-stage fixed bed reactor system," Fuel Process. Technol., 89, 1306-1316.

Xie, H., Yu, Q., Wang, K., Li, X. and Qin, Q. (2014). "Thermodynamic and experimental study on the steam reforming processes of bio-oil compounds for hydrogen production," in Energy Technology 2014: Carbon Dioxide Management and Other Technologies, Wiley-TMS, New Jersey.

Xiu, S. and Shahbazi, A. (2012). "Bio-oil production and upgrading research: A review," Renew. Sustain. Energy Rev., 16, 4406-4414.

Xu, Q., Xie, D., Wang, F. and Yan, Y. (2013). "Mechanism of hydrogen production by the catalytic steam reforming of bio-oil. Energy Sources, Part A Recover," Util. Environ. Eff., 35, 1028-1038.

Yan, C.-F.F., Hu, E.-Y.Y. and Cai, C.-L.L. (2010). "Hydrogen production from bio-oil aqueous fraction with in situ carbon dioxide capture," Int. J. Hydrogen Energy, 35, 2612-2616.

Received: April 15, 2018

Sent to Subject Editor: August 31, 2019

Accepted: September 30, 2019

Recommended by Editor in Chief Alberto Bandoni 